\section{BAUDELAIRE, BeNJAMIN E A ARQUITETURA D'AS FLORES DO MAL}

Iniciamos aqui, com o realce de um ponto específico que parece constituir uma fissura na quase continuidade, que historicamente, para muitos leitores, se estabeleceu entre a obra de Baudelaire e os ensaios benjaminianos a ele dedicados na década de 1930: a definição teórica baudelairiana da arte moderna, presente sob a forma de "uma teoria racional e histórica do belo". "Esta parece ser uma das formulações teóricas mais insistentes do próprio Baudelaire. O comentário benjaminiano sobre esta teoria resume-se, no entanto, à primeira vista, a uma sumária rejeição. "A teoria da arte moderna é, na visão baudelairiana da modernidade, o ponto mais fraco", diz Benjamin em "A Paris do Segundo Império em Baudelaire". Este comentário se segue a uma passagem citada, na qual Baudelaire introduz no conceito de beleza uma separação entre "um elemento eterno e imutável e um elemento relativo e limitado. Este último, fornecido pela época, pela moda, pela moral, pelas paixões." A citação, resumida e com as tradicionais lacunas marcadas por reticências, típicas do modo benjaminiano de citar, é acompanhada laconicamente pelo seguinte comentário: "Não se pode dizer que isso vá fundo na questão". Esta recusa, por parte do crítico filósofo, de uma teoria proposta pelo próprio autor objeto de sua crítica, tem para nós um significado de particular importância. $\mathrm{Na}$ formulação teórica de Baudelaire, resumida por Benjamin, o fascínio pelo aspecto inaudito do presente seria a forma que a beleza, fenômeno no fim das contas ahistórico, teria de se reatualizar. Por mais que procure enfatizar a importância desta face presente do belo, imprescindível para que possua sabor e força intuitiva, é de um mesmo que se manifesta diferenciadamente que Baudelaire se refere ao usar o termo beleza. A formulação desta teoria, no entanto, é apenas um dentre muitos outros sinais de que Baudelaire estava empenhado em pensar uma crise e a inevitável mutação na experiência da obra de arte, e é também, ao menos para Benjamin, o sinal mais fraco. Ao rejeitar de modo aparentemente sumário a formulação baudelairiana da "beleza moderna", Benjamin está, na verdade, apenas iniciando sua própria empreitada, tomando como
* (BAUDELAIRE, Charles "O pintor da vida moderna". A modernidade de Baudelaire. Trad. Suely Cassal. Rio de Janeiro: Paz e Terra, 1988: 162.)

(BENJAMIN, Walter. "A Paris do Segundo Império em Baudelaire." Obras escolhidas III: Charles Baudelaire, um lírico no auge do capitalismo. Trad. José Carlos Martins Correa e Hemerson Alves Baptista. São Paulo: Brasiliense, 1994: 81.)

* (Idem.) 
base uma possível "arquitetura secreta" ${ }^{1}$ de As Flores do Mal. Nesta empreitada, Benjamin irá perseguir o que ele mesmo indicará como tendo sido também o objetivo de Baudelaire: pensar a experiência da obra de arte como o lugar de cruzamento de forças históricas, que dão a conhecer um imbricamento entre a crise da experiência tradicional e o prenúncio de tendências futuras. Vejamos como, em seus ensaios sobre Baudelaire, em especial no segundo, Benjamin lança as bases de uma reflexão sobre a experiência e o lugar da arte no mundo moderno, e que poderia ser desdobrada para pensar o contemporâneo.

A construção benjaminiana, tomando como partida a recusa da teoria da "beleza moderna", tem sua formulação inicial no primeiro dos três grandes ensaios dedicados ao poeta. Ali, em "A Paris do segundo Império em Baudelaire", Benjamin aponta para a desconexão entre o tema da "beleza moderna" e o da arte antiga. "A teoria da arte moderna deveria ter visado a um debate com a arte antiga. Baudelaire nunca tentou coisa semelhante", diz Benjamin. $\mathrm{E}$ acrescenta que "nenhuma das reflexões estéticas da teoria baudelairiana expõe a modernidade em sua interpenetração com a antiguidade como ocorre em certos trechos de As Flores do Mal." ${ }^{\text {* }} \mathrm{O}$ termo "antiguidade" surge aí como sinônimo de era modelar greco-romana, presente como fonte de parâmetros formais a serem adotados pelos poetas modernos, e como repertório de exemplos de obras bem sucedidas na aventura de atravessar os tempos conservando o interesse. Querer ser lido como os clássicos: essa teria sido uma pretensão de Baudelaire. No decorrer do primeiro ensaio benjaminiano, porém, o termo antiguidade vai ganhando rapidamente outras conotaçôes. A caducidade precoce, entrevista na face da Paris Haussmaniana, é um termo chave para o início desta transformação. Nesta altura da argumentação, antigo, então, não significa mais eterno e estável. $\mathrm{O}$ antigo passa a significar uma faceta do próprio presente, e não a permanência de elementos imutáveis. $\mathrm{O}$ antigo invade o novo quando o futuro comum de ambos se revela o mesmo, a ruína. Benjamin vai então sublinhar, mesmo num ensaio como "O pintor da vida moderna", a vinculação que Baudelaire faz entre o luto e as formas da moda então em pleno vigor, como os fraques: "Nós todos celebramos algum enterro", cita

\footnotetext{
${ }^{1}$ Benjamin aceita esta hipótese, embora com certa cautela: "Se existe realmente uma arquitetura secreta neste livro...". "Sobre alguns temas em Baudelaire". Op. Cit.: 132.
} 
Benjamin, que afirma: "Essas idéias contribuíram para a profunda fascinação que a transeunte enlutada do soneto exerceu sobre o poeta", se referindo ao famoso soneto "A uma passante".

Único poema d'As flores do mal transcrito na íntegra nos dois principais ensaios escritos por Benjamin sobre Baudelaire, o soneto pode ser visto como o ponto chave da interpretação benjaminiana. Vimos que Benjamin se refere à personagem do soneto como "a transeunte enlutada". Com isto, ele quer enfatizar que a experiência perceptiva propiciada pelo encontro entre o transeunte na multidão e a passante está, em primeiro lugar, inteiramente sintonizada com o redesenhado sentido da palavra antiguidade. Trata-se, na expressão benjaminiana, jocosa, mas prenhe de conexões, de "um amor não tanto à primeira quanto à última vista", * signo do entrelaçamento entre a morte e o brilho erotizado que pode assumir a novidade.

O elemento em que se dá este tipo de percepção é representado pela multidão. A multidão é o meio ambiente do "caleidoscópio dotado de consciência”. É da afinidade entre transeunte e multidão que brota tal caleidoscópio, e é no campo visual deste que surge a passante. No ensaio "Sobre alguns temas em Baudelaire", que é uma segunda versão de "A Paris do Segundo Império", o tema da multidão como meio perceptivo é intensificado. Neste contexto, diz Benjamin a respeito do poema da passante: "É uma despedida para sempre, que coincide, no poema, com o momento do fascínio. Assim, o soneto apresenta a imagem de um choque..." É a partir do termo "choque" que Benjamin continua, com outro aparato teórico, o que havia iniciado em "A Paris do Segundo Império": investigar o soneto como emblema central de uma forma histórica de percepção. Diríamos, no entanto, que, no segundo ensaio sobre Baudelaire, o soneto aponta para dois caminhos. No primeiro destes, que é uma continuação do tema do primeiro ensaio, o soneto alegoriza um modo de sensorialidade, típico da vivência do transeunte na multidão. $\mathrm{O}$ choque é apresentado como uma vivência corriqueira da rua moderna, não apenas pelos acotovelamentos e esbarrões, mas sim e muito mais pelas constantes e bruscas interrupções que fragmentam a percepção. Os olhares constantemente lançados em todas as direções pelo transeunte atendem predominantemente a funções de segurança, buscam proteger a integridade da consciência do excesso de estímulos provocados pelo entrecruzamento de tantas relações e significados, impressos nas coisas e na
* ("A Paris do Segundo Império". Op. cit.: 76.)

" ("Sobre alguns temas em Baudelaire". Op. cit.: 118.)

"(Idem.) 
- (BENJAMIN, Walter. Obras escolhidas II. Rua de mão única. Trad. de Rubens Rodrigues Torres Filho e José Carlos Martins Barbosa. São Paulo: Brasiliense, 1997: 15.) multidão. O conjunto das descrições que Benjamin faz do olhar do citadino culmina na sua associação com o princípio formal do cinema, o corte. Tal como na narrativa cinematográfica, a memória do citadino terá que aprender a manejar, sem traumas com o corte, a descontinuidade e a fragmentação. É a apresentação de um tal corte que o soneto da passante nos dá. Benjamin já havia dito, em texto de quase uma década antes, que "as ruas parisienses dos poemas de Baudelaire só existiram depois de 1900", ou seja, na época em que o cinema já se afirma como o lugar privilegiado de exercício do mesmo princípio perceptivo que o habitante das grandes cidades do século XIX exercita nas ruas.

A descrição do choque se desdobra como uma rica teoria histórica da percepção. A tese de que a percepção sensorial não consiste num atributo metafísico da essência do homem atravessa a obra benjaminiana, especialmente a partir do livro sobre o drama barroco. Esta tese terá seu momento culminante no segundo ensaio sobre Baudelaire, onde se articula com outra teoria que é a da historicidade da memória. Ambas as teorias se abrigam sob o tema denominado crise da experiência. A percepção sensorial e a memória modernas virão à tona através de um contraste com formas declinantes ou tendentes a desaparecer, modos de perceber e lembrar que sinalizam para outro tipo vida, outros homens para os quais a situação sensorial emblematizada pela passante não passaria de um caso fortuito. Formas arcaicas de memória, tais como as que são abordadas no ensaio sobre o contador de histórias, ou modalidades de percepção sensorial diversas daquela que se anuncia como dominante na cidade moderna, modos de perceber que são abrigados sob o misterioso e sedutor nome de aura, servirão como único contraste capaz de revelar a forma da memória e percepção modernas.

É tendo como pano de fundo este contraste interdependente entre choque e aura que Benjamin explora diversas figuras alegóricas, algumas provenientes da obra de Baudelaire, como o jogador, o transeunte na multidão e outras, como o operário não especializado, não. $\mathrm{O}$ que os une ao transeunte que encontra a passante, $\mathrm{e}$ configura uma constelação de alegorias, é a vivência do choque. $\mathrm{O}$ constelamento desta diversidade de figuras demonstra o quanto a situação do encontro com a passante está longe de ser aleatória ou mera curiosidade urbana entre outras. O recurso de Benjamin a estas figuras alegóricas busca conquistar uma dimensão ao mesmo 
tempo estética e histórica para sua leitura da obra baudelairiana. $\mathrm{O}$ termo "estética" deve, em princípio, conservar aqui certas conotações antigas, ou seja, a de dimensão geral da sensorialidade, a aísthesis. A obra de arte, por sua vez, seria o lugar da mais concentrada e significativa manifestação das condiçōes estéticas dominantes: a estética então seria, em sua versão benjaminiana, a pergunta pelo lugar da obra de arte no contexto de uma investigação da historicidade da aisthesis. Nesta investigação a obra de arte tem precedência, pois, paradoxalmente, é dela que parte a investigação estética geral. Só porque a aisthesis moderna aparece de modo tão intenso na obra de Baudelaire é que Benjamin pôde tecer este mapeamento geral da sensorialidade predominante na época em que foram escritas as Flores do Mal, através de uma rede de analogias.

Para Benjamin, "Baudelaire inseriu a experiência do choque no âmago de seu trabalho artístico." ${ }^{\prime *}$ faz referência ao poema em prosa "Le confiteor de l'artiste", que resume então com essas palavras: "a imagem crua de um duelo, em que o artista, antes de ser vencido, lança um grito de susto."* A este duelo, Baudelaire chama de "étude du beau", "expressão a que Benjamin não faz alusão. Vivências corriqueiras como a do transeunte na multidão são marcadas pela atitude defensiva e precavida que procura antes aparar o choque, e depois, só depois, perceber algo. O insucesso neste afã defensivo conduziria a um trauma. Benjamin chega a falar, a propósito de Baudelaire, de "tipos traumatófilos". A experiência perceptiva posta em curso pela súbita aparição da passante teria, portanto, algo do ato de acolher um choque sem reservas. A "estranha esgrima”, ou seja, o estudo do belo terminaria por se cristalizar num susto, numa falha em atenuar e controlar a intensidade dos estímulos, e, por conseqüência, numa capitulação da arte frente a uma pretensa força maior chamada, se quisermos, de realidade. A assunção do choque prenuncia uma poética que dá um passo além na direção do estilhaçamento estético, podendo, em certos casos, abraçar sem reservas o fascínio embasbacado pelo novo. Em outros casos, a arte pode tentar transitar pelo espaço de silêncio decorrente de tal impossibilidade de aparar o choque.

Para nós, porém, o decisivo, e o que talvez explique o destaque concedido ao poema da passante, é que ele sugere uma situação perceptiva ainda não inteiramente fragmentada, ou antes, trata-se de um fragmento que ainda guarda um fiapo de lembrança do todo do qual um dia, talvez, tenha feito parte.
" ("Sobre alguns temas em Baudelaire". Op. cit.: 111.)

" (Idem.)

* (BAUDELAIRE, Charles. CEuvres complètes. Paris: Seuil, 1987)

"("Sobre alguns temas em Baudelaire". Op. cit.: 111.) 
- ["Im Witwenschleier, schleierhaft durch ihr stummes Dahingetragenwerden im Gewühl, kreutz eine Unbekannte den Blick des Dichters". Tradução nossa.] (BENJAMIN, W. Gesammelte Schriften. I-2. Frankfurt: Suhrkamp, 1994: 623.)

" ("Sobre alguns temas em Baudelaire". Op. cit.: 133.)

(Gesammelte Schriften I1:195.)

(Op. cit.: 194.)
A passante, portanto, aponta para dois lados: por um lado anuncia uma fragmentação radical, por outro, sinaliza na direção contrária. Nisto consiste a segunda e decisiva vertente da leitura realizada por Benjamin em "Sobre alguns temas". Para percebermos isto, temos de compreender o novo relevo dado pelo ensaio ao luto da passante. Aqui vamos tomar a liberdade de destacar este relevo, e nos prendermos à palavra "véu", pois acreditamos que é este signo da passante que a conecta ao que Benjamin cogita ser uma possível "arquitetura secreta" de As Flores do Mal. É deste modo que Benjamin introduz o comentário direto ao poema: "Sob o véu de viúva, velada em seu mudo ser carregada pela multidão, uma desconhecida cruza o olhar do poeta." ${ }^{*}$ Benjamin transforma a expressão "en grand deuil" do poema em algo bem mais específico como um "véu de viúva" ("Im Witwenschleier"). O tema do véu é apresentado no ensaio "Sobre alguns temas em Baudelaire", na altura da seção $\mathrm{V}$, logo após a transcrição do soneto, e só é retomado na seção $\mathrm{X}$, embora aí não mais referido à passante. Ali, na mais longa nota de pé de página do texto, Benjamin cita seu próprio ensaio de juventude sobre as Afinidades Eletivas, de Goethe: "O belo pode ser definido como aquilo que apenas 'permanece essencialmente idêntico a si mesmo quando velado.'”* A palavra aí utilizada não provém do mesmo radical que na expressão "véu de viúva", mas sim de um termo que, no contexto, se torna sinônimo. ${ }^{2} \mathrm{O}$ trecho do ensaio sobre Goethe continua deste modo: "Em tudo o mais, a aparência pode enganar, mas a bela aparência é o véu estendido diante disto que exige, mais que tudo, ser velado. Pois o belo não é nem o véu nem o velado, mas o objeto em seu véu. Frente ao belo, em conseqüência, a idéia do velamento se transforma na idéia da impossibilidade de desvelar."

No ensaio sobre Goethe, o contexto em que Benjamin formula estas e diversas outras afirmações a respeito do caráter essencialmente velado do belo é o de uma discussão onde repudia a noção de beleza enquanto "verdade tornada visível". Trata-se, portanto, de uma discussão central da estética tradicional, na qual Benjamin se insere, tomando partido da posição que defende a indecifrabilidade da bela aparência, mesmo que repudiando o nível em que Kant, neste ponto um possível aliado, teria colocado a questão. $\mathrm{O}$

\footnotetext{
2 "Das Schöne in seinem Verhältnis zur natur kann als das bestimmt werden, was 'wesenhaft sich selbst gleich nur unter der Verhüllung bleibt". Grifo nosso. Op. cit.: 639.
} 
caráter de aparência do belo não deve ser compreendido, para Benjamin, como um véu sensível a ser retirado, desvelando então uma hipotética essência inteligível. "A aparência”, diz, "é justamente isto: de modo algum um véu inutilmente lançado sobre as coisas em si, mas sim o véu que deve cobrir as coisas para nós. Divina é, de qualquer modo, a necessidade que lhes impõem este véu..."* De origem "divina", e não fruto de "uma relação" de cunho subjetivo, como queria Kant. Na seção X de "Sobre alguns temas em Baudelaire", Benjamin retoma esta discussão estética, o que diferencia bastante este ensaio de "A Paris do Segundo Império". É decisiva a importância agora conferida a dois outros poemas de As Flores do Mal, as "Correspondências" e "A vida anterior". A experiência evocada nestes sonetos diz respeito a uma esfera perceptiva muito diversa daquela a que está submetido o homem moderno. A indecifrabilidade da bela aparência torna impossível remetê-la a algo de próximo, de familiar, ou de igual. A vivência do eterno retorno do novo lhe é inteiramente estranha. À experiência perceptiva que consiste em captar o mistério ou a irrepetibilidade irremissível dos fenômenos, Benjamin chamou de captar a aura. Este modo de percepção é, tal como o moderno, descrito como forma histórica. Perceber a aura de uma coisa é, como sugere esta palavra de forte apelo metafórico, encontrar-se inserido em sua atmosfera, envolvido por sua aragem, imergir no mesmo elemento que a coisa observada. Para tanto, é preciso participar da tradição em que o objeto encontra sua significação, participação esta que não leva, no entanto, à proximidade. Só quando observador e coisa observada participam da mesma tradição, o observador sente seu olhar correspondido pela coisa observada. "Perceber a aura de uma coisa significa investí-la do poder de revidar o olhar", ' diz Benjamin, inserindo uma tonalidade na palavra correspondance.

O belo, portanto, é o murmúrio de uma correspondência. A inacessibilidade da origem desta correspondência, no entanto, é o véu. Apenas velada, mantida enquanto "fenômeno irrepetível de uma distância”, ${ }^{3}$ dá-se a beleza, nome laico de um tipo de perceptibilidade que, historicamente, teria tido lugar de início na relação

\footnotetext{
${ }^{3}$ Tradução nossa de "einmalige Erscheinung einer Ferne", da célebre definição da aura, do ensaio "Das Kunstwerk im Zeitalter seiner technischen Reprodutizierbarkeit”. In. Gesammelte Schriften I-2: 440. Na tradução brasileira da primeira versão do ensaio, lemos "a aparição única de uma coisa distante". In. Obras escolhidas I. Magia e técnica, arte e política. Trad. José Paulo Rouanet. São Paulo: Brasiliense, 1987.
} 
com a imagem cúltica, velada por valor mágico ou religioso, fazendo parte, portanto, da esfera divina a que Benjamin aludia no ensaio sobre as Afinidades eletivas. Baudelaire teria sido o poeta que, por possuir uma aguda compreensão do caráter aurático e cúltico da experiência perceptiva, concentrado na palavra belo, pôde então avaliar a extensão e a importância da crise na estrutura da percepção, metonimicamente localizável na vivência urbana, que seria, por sua vez, manifestação e antecipação de mudanças históricas irreversíveis. Para Benjamin, a formulação teórica baudelairiana da "beleza moderna" não faz nem de longe justiça à extensão desta crise.

Na leitura arquitetônica d'As Flores do Mal proposta por Benjamin, esta crise só pode ser pensada se a colocamos à percepção do choque, não em sequiência linear com a das correspondências, mas sim, emoldurada por estas. O pensamento estético de Walter Benjamin é a formulação teórica desta crise, ou a criação desta crise no pensamento. Só é possível pensar o choque, e não ser tragado por ele, se inserimos nele a marca de uma ausência, justamente, a da aura. O papel do soneto "A uma passante" é então decisivo. A passante emblematiza uma experiência-limiar, espécie de umbral no qual a poética de Baudelaire se colocou com insistência. Apesar de o soneto deixar claro que o observador espera ainda a retribuição do olhar, marca de uma expectativa tradicional, e que a passante de fato o retribui, a efetivação da "promessa de felicidade" implícita nesta correspondência de olhares é adiada para sempre, remetida a uma vida irremediavelmente perdida, contagiando o observador com o luto que veste a agradável visão. $\mathrm{O}$ luto que veste a passante vela para sempre o lugar desta correspondência, e é esta afinidade no velar, que une a imagem da passante e a vivência do transeunte na multidão, o que faz da "fugitive beauté" uma experiência estética chave. O caráter fortuito do encontro com a passante enlutada é sinal da precariedade e do risco em que se encontra tal experiência.

Outros tantos poemas de As flores do mal celebram o fracasso de até mesmo se chegar a tal limiar debruçado sobre a perda. Segundo Benjamin, o que "torna inconfundíveis" As flores do mal é o "fato de terem extraído (...) poemas que em nada ficam devendo àqueles em que as correspondences celebram suas festas", justamente extraí-los do "fracasso" em recuperar a lembrança da aura. Este fracasso, porém, só se torna visível por que é emoldurado pela lembrança da percepção aurática, emblematizada pelas correspon- 
dances. Os diversos poemas dedicados ao spleen seriam por isso, na leitura benjaminiana, também componentes imprescindíveis da arquitetura do livro. Entre os dois extremos desta, para nós, situa-se o soneto da passante, isto é, entre o "Ideal" das correspondências e sua inacessível origem numa "pré-história", numa "vida anterior" irremediavelmente perdida, mas presente enquanto diferença no seio da vivência moderna, e os poemas spleen, onde a "Terra volta ao simples estado natural", onde "nenhum sopro de pré-história, nenhuma aura” é percebida. Nossa aposta é a de que não podemos tomar este "nenhuma aura" ao pé da letra. Pois, por um lado, o choque só é pensável emoldurado pela experiência aurática, por outro, a aura só nasce como tema do pensamento a partir da experiência do choque. Esta é a grande e abismal diferença entre o tema benjaminiano da aura e as formulações, por exemplo, de Kant sobre a beleza que, em certos aspectos e guardadas as diferenças, lhe podem ser aproximadas. Os conceitos benjaminianos de choque e de aura são históricos, e isto dentro de uma concepção não linear de história. Ou seja, a aura não é simplesmente uma etapa deixada para trás, dentro de uma linha temporal infinita e homogênea, e a estética do choque não se reduz a uma simples etapa nova encontrada a seguir no percurso reto desta mesma linha.

Esta é a origem, para nós, da retomada do tema do véu por Benjamin, justo quando trata do luto da passante. $O$ véu se dá, na modernidade, como luto. A passante emblematiza o duplo significado que possui, ao menos em nossa língua, o verbo velar. O soneto da transeunte enlutada seria, nesta nossa leitura da leitura arquitetônica de Benjamin, a passagem ou o umbral sem espessura entre a percepção do choque ou do corte que fragmenta e a lembrança da unidade. Sem esta última, uma estética do puro choque conduziria às aporias que cercam o ensaio "A obra de arte na época de sua reprodutibilidade técnica", com sua oposição binária entre a percepção aurática e o modo moderno de participação na obra de arte. Julgamos que, apesar de seu caráter enigmático e inconclusivo, em sua leitura arquitetônica d'As Flores do Mal, Benjamin esteve mais próximo de pensar o "pós-aurático" do que em seu ensaio sobre o cinema. Neste sentido, o ponto mais alto do pensamento maduro de Walter Benjamin sobre a arte é, também, um desdobramento da obra baudelairiana. Não seria despropositado afirmar que, recusando a teoria da arte moderna baudelairiana, Benjamin estaria abrindo caminho para a explicitação de um pensamento 
mais próprio a Baudelaire do que aquele, que o pensamento histórico do poeta francês encontra, tal como na formulação romântica tão cara ao jovem Benjamin, sua continuação e intensificação na obra de seu mais eminente crítico. Nesta sua retomada e continuação, o poema da passante funciona como o vértice de um leque, de uma gama de nuances possíveis de produção e recepção da arte, ponto articulador de um espectro de sentidos que vai desde as correspondências em sua plenitude, mesmo que apenas através da memória de sua ausência, até o completo esquecimento destas, representado pela vivência do tédio e do desencantamento sem volta do mundo, dos quais Baudelaire provou ser possível "extrair" poemas por contraste do que se perdeu, do que está se perdendo, o que prenuncia inúmeras vertentes contemporâneas. Caso realmente precisemos conservar o termo beleza, diríamos que o seu sentido tem de cobrir no mínimo todo este espectro, e não apenas um ou outro de seus pontos. Que a palavra beleza resista a esta abrangência, é algo que tem sido constantemente posto em dúvida. A não emergência de outro termo que represente a resistência à indiferenciação da arte para com outros objetos, porém, é algo igualmente fácil de constatar. Como provisória conclusão, cremos ser particularmente interessante para os desafios do pensamento estético hoje, encontrar na leitura benjaminiana de As Flores do Mal os elementos para uma teoria multifacetada, uma teoria ao mesmo tempo do estilhaçamento e da convivência dos possíveis sentidos que ainda possa ter a palavra arte. 


\section{Bernardo Barros Coelho de Oliveira}

Bernardo Barros Coelho de Oliveira é Doutor em Filosofia pela UFRJ e professor do Depto. de Filosofia da Universidade Federal do Espírito Santo. Publicou o livro Olhar e narrativa: leituras benjaminianas (Vitória: EDUFES, 2006). E-mail: bbco@ebrnet.com.br

\section{Resumo}

Este artigo tenta explorar a idéia, sugerida de modo cauteloso por Walter Benjamin no ensaio "Sobre alguns temas em Baudelaire", de uma "arquitetura secreta" d'As flores do mal, ou seja, a de um desenho que unificaria os poemas e tornaria visível o frágil equilíbrio entre os momentos do livro em que a percepção aurática é celebrada e aqueles em que a sua perda é afirmada sem reservas. $O$ poema "A uma passante" funcionaria, nesta leitura arquitetônica, como passagem privilegiada entre estes dois extremos, e nos levaria a entrever um caminho para pensar a percepção moderna da obra de arte não como uma simples superação do aurático, mas sim como uma tensa dialética entre choque e luto pela unidade perdida.

\section{Abstract}

This article tries to explore the idea, cautiously suggested by Walter Benjamin in "Some motifs in Baudelaire", concerning a "secret architecture" in The Flowers of Evil, a drawing that would be able to unify the poems and show the fragile harmony between the moments of the book in which the auratic perception is celebrated, and those in which its loss is undoubtedly affirmed. The poem "To a Passerby" would function, in this architectonic approach, as a privileged passage between those extremities, and would show us a way to ponder the modern perception of the work of art, not as a simple overcoming of the auratic, but as a tense dialectic between shock and mourning for the lost unity.

\section{Résumé}

Cet article essaye d'explorer l'idée, suggérée avec précaution par Walter Benjamin dans l'essai "Sur quelques thèmes baudelairiens", d'une "architecture cachée" des Fleurs du mal, c'est-à-dire d'un dessin qui unifierait les poèmes et rendrait visiblel'équilibre fragile entre les moments du livre dont la perception auratique est célébrée et ceux dont la perte est afirmée sans réserves. Le poème "À une passante" fonctionnerait, dans cette lecture architectonique, comme passage privilégié entre ces deux extrêmes, et nous emmènerait à entrevoir une voie pour penser la perception moderne del'oeuvre d'art non pas comme un simple dépassement de l'auratique, mais comme une dialectique tendue entre le choc et le deuil de l'unité perdue.
Palavras-chave: Filosofia da arte; Crítica; Poesia.

Key words: philosophy of art; criticism; poetry.

Mots-clés: Philosophie de I'art; Critique; Poésie.

Recebido em 04/05/2007

Aprovado em 30/06/2007 